\title{
EXPERIMENTAL SYSTEM FOR THE OPTIMIZATION OF THE PARALLEL MANIPULATOR CONTROL
}

\author{
NGUYEN XUAN VINH ${ }^{1}$, LE QUOC HA ${ }^{2}$, NGUYEN NGOC LAM ${ }^{3}$, LE HOAI QUOC ${ }^{4}$, \\ AND NGUYEN MINH THANH ${ }^{5}$ \\ ${ }^{1}$ University of Science, Vietnam National University Ho Chi Minh City; \\ nguyen.xuan.vinh@gmail.com \\ ${ }^{2}$ Vietnam Institute of Electronics, Informatics and Automation; lequochavn@yahoo.com \\ ${ }^{3}$ Vietnam Institute of Electronics, Informatics and Automation; \\ lamnguyenngoc_ne@yahoo.com.vn \\ ${ }^{4}$ Saigon Hi-tech Park; lhquoc.shtp@tphcm.gov.vn \\ ${ }^{5}$ Saigon Hi-tech Park; nmthanh.shtp@tphcm.gov.vn
}

\begin{abstract}
This paper presents the results of an experimental system design for the optimization of parallel manipulator control based on an optimal configuration. The experimental system is an open design for various different configurations and controllers to support parallel manipulator research and applications. Traditional PID control and self-tuning fuzzy PID control algorithm are applied for motion control of parallel manipulator. The quality system standard will be analyzed and compared with simulation results. The system can be a useful tool for research and training.
\end{abstract}

Keywords. Parallel manipulator, robot experimental system, robot controller, fuzzy theory, PID controller, self-tuning.

\section{INTRODUCTION}

For recent years, parallel manipulators have been applied in several fields such as mechanical precision machining, assembly machinery, surgery equipment, astronomy, geodesy and moving simulators... [1-4]. As it is well known, high stiffness, high precision with high speed of movements, heavy load possibility and low inertia force are outstanding advantages of parallel robots. However, their drawbacks are limited workspace, complicated design and manufacture, high cost and the existence of singularities in their workspace [5-11]. Therefore, the study of optimization of design and control is important to minimize their noted drawbacks. Example of optimization for parallel manipulators papers in $[12-17]$ and singularity in $[5-11,18]$.

This paper presents a continuous research on optimal design and control for Gough-Stewart platform. The multi-criteria optimization using genetic algorithm (GA) and a Pareto optimal set is considered in [15-17], theory of screws for determination of singularity in [18]. Based on the optimal design, controller improvement using a fuzzy combined genetic algorithm is proposed in [19]. In this paper, an experimental system is reported to confirm the presented simulation results and support for subsequent studies.

Because parallel robot can be defined as closed-loop chain mechanism, it has nonlinear behavior and complex control $[20,21]$. To make the payload platform moving, it is needed to synchronize the movement of all actuators. Combined actuators must have smoothly and accurately controlled at 
the same time. It is a difficult requirement of controller design for parallel mechanism. In Vietnam, some research results show that the parallel robots are gradually applied in areas such as mechanical, industrial applications [22-30]. However, the open parallel experimental system for study and research is still necessary.

\section{SYSTEM DESIGN AND PERFORMANCE}

\subsection{Design and performance of mechanical part}

The Stewart-Gough Platform [1,2] has a base platform and a payload platform connected by six prismatic joints attached via universal joints in figure 1. Normally, linear motors are used for actuators of parallel robot to ensure needed precision in the mechanical machine [29]. However, with the goal of building an experimental system with low cost, DC motor screw actuators are used in our system.

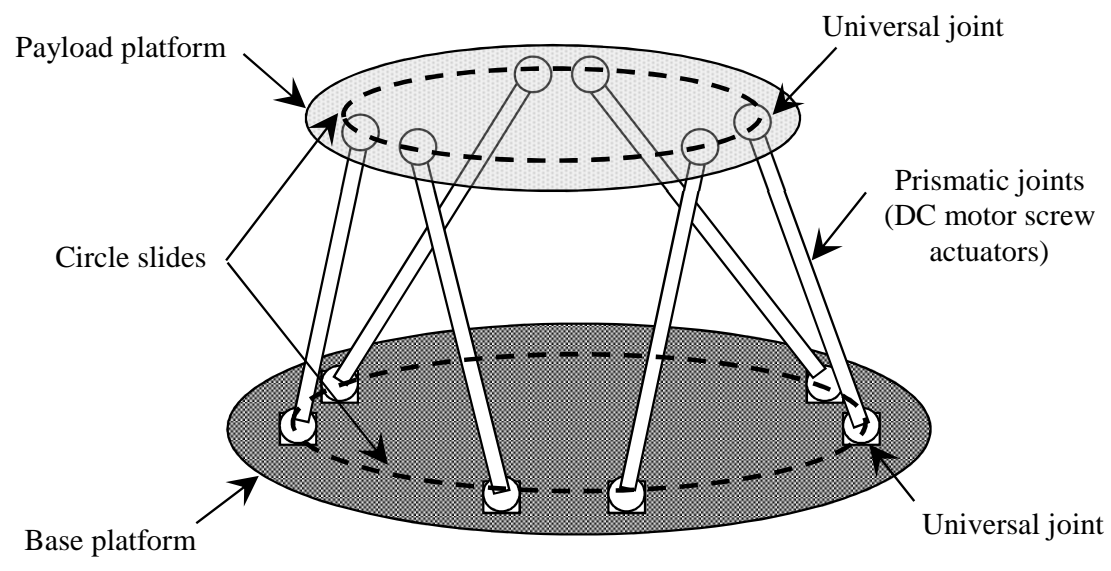

Figure 1: Stewart-Gough Platform

The universal joints were arranged in circle slides to study working variants and configurations of the parallel manipulator. Inside encoders can feed back the real position of DC motor screw actuators. Top and bottom switches were used to warrant the limited motion. The design and technical parameters of mechanical part is illustrated in Figure 4 and Table 1.

\subsection{Design and performance of control system}

As mentioned above, the control of Stewart-Gough Platform is highly complicated due to the existence of nonlinear features and complex dynamics [20,21]. Therefore, the control system should be open, flexible, and it must make it easy to apply different control algorithms with monitoring functions and real-time data acquisition.

The proposed control system structure is shown in Figure 2. Control tasks of the control system are distributed as follows:

The computer performs kinematic and dynamic calculations, monitoring, real-time data acquisition with user interface and control communication. In the motion control of parallel robot, the computer calculates the needed positions of manipulator and gets real actuators positions from master controller. These data are scored to analyze and evaluate the controller quality. In addition, working modes and control algorithms will be chosen on user interface. 


\begin{tabular}{|l|c|}
\hline Base platform radius & $0.2(\mathrm{~m})$ \\
\hline Payload platform radius & $0.15(\mathrm{~m})$ \\
\hline Actuator limit & $0.32(\mathrm{~m}) \leq l i \leq 0.52(\mathrm{~m})$ \\
\hline Actuator max speed & $16(\mathrm{~mm} / \mathrm{s})$ \\
\hline Rating Voltage & $100($ pulse per rotation $)$ \\
\hline Encoder & $\mathrm{X} / \mathrm{Y} / \mathrm{Z}: 300 / 300 / 200(\mathrm{~mm}) ;$ \\
Workspace limitation & $\alpha / \beta / \gamma($ Roll $/$ Pitch $/ \mathrm{Yaw}): \pm 0.43(\mathrm{rad})$ \\
\hline Max load & $2(\mathrm{~kg})$ \\
\hline Static precision & $\pm 25(\mu \mathrm{m})$ \\
\hline Total weight & $5(\mathrm{~kg})$ \\
\hline
\end{tabular}

Table 1: Technical parameters of the mechanical part

The experimental system has a master controller (CPU) and six slave controllers (Drivers). The master controller plays an important role in the distribution of the motion control signals between the actuators. In the control stages, the master controller receives the reference positions from the computer and processes it together with the real position and speed data sent to it by the slave controllers. Then the master controller also calculates and outputs the necessary speeds of actuators to slave controllers. As a result, the robot system is ensured to combine the synchronized motion between actuators. The real position and velocity of six actuators will be sent to the computer for data monitoring and acquisition in real time.

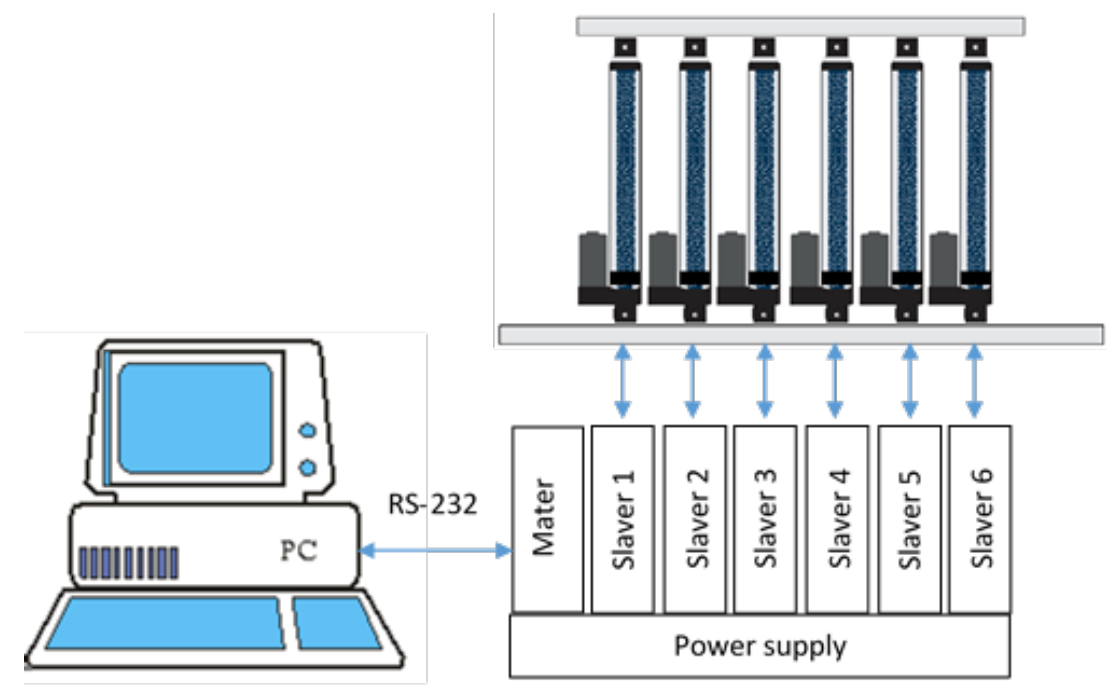

Figure 2: Control system structure of the experimental system

The slave controllers execute motion control of DC motor screw actuators according to the reference position and velocity from master controller through power electronic driver and inside encoders. Control algorithms, such as PID, Fuzzy-PID... are designed and integrated with the subprograms in C language. It can easily adjust control parameters according to the requirements of the study. The controller part of the experimental system is illustrated in Figure 3 and Table 2. 


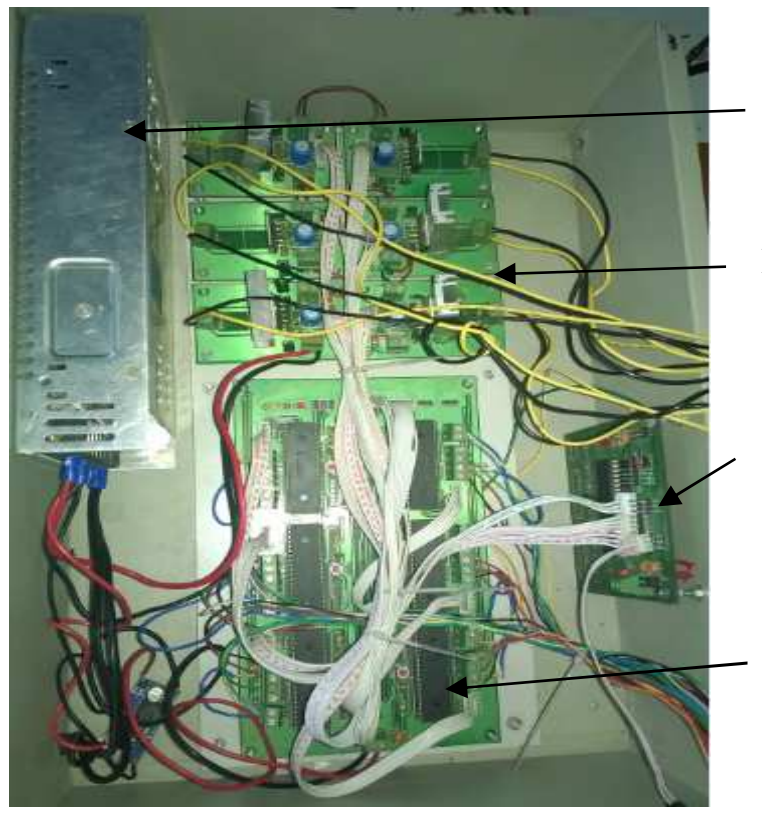

Power supply

Power electronic driver

Slave controllers

Figure 3: Controller part of the experimental system

\begin{tabular}{|l|c|}
\hline Masters chip & PIC18F4550 \\
\hline Slavers chip & DSPIC30F4011 \\
\hline PC-Master communication & RS232 $(115.2 \mathrm{Kps})$ \\
\hline Master-Slaver communication & SPI (clock 1 Mbps) \\
\hline Power electronic driver & LM18200 $(20 \mathrm{kHz})$ \\
\hline 2 cascades loop controller (speed, position) & PID, Fuzzy-PID \\
\hline Sample time & 1 (ms) \\
\hline Support software & Real-time Windows Targets - MATLAB 2014 \\
\hline Programming for PIC, DSPIC & CSS-C Compiler v4.114 \\
\hline
\end{tabular}

Table 2: Technical parameters of control system

The implemented experimental system for the optimization of the parallel manipulator (Stewart-Gough Platform) control is illustrated in Figure 4.

The experimental system is designed for the study of parallel manipulator configurations and optimized controller. On this system, the control algorithms can be tested regarding their ability to monitor, control and applicability for the optimization of the motion of the parallel manipulator. The following section presents results of the optimal control of Stewart-Gough platform.

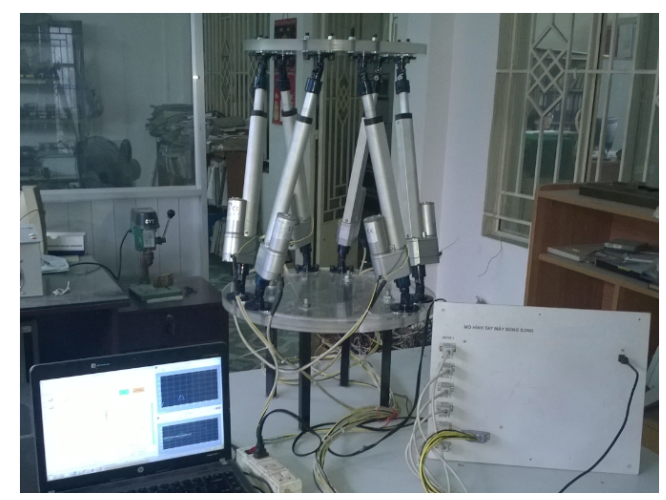

Figure 4: The experimental system (Stewart Gough Platform) 


\section{OPTIMAL CONTROL FOR STEWART-GOUGH PLATFORM}

As mentioned above, it is difficult to control the motion of parallel mechanisms. Because of having combined actuators, their workspace is multi-form and the control solutions are normally complicated. Actuators must be controlled synchronously and precisely. In this section, a multicriteria optimal configuration of StewartGough platform will be designed to apply control algorithms with fixed work space. The kinematic and dynamic properties of the optimal configuration are calculated by MATLAB-SIMULINK. The traditional PID and self-tuning fuzzy PID (FuzzyPID) algorithms will be designed and applied for motion control with the optimal configuration of Stewart-Gough platform. The experimental results will be examined and analyzed based on the quality standards of the system through the actuators transient responses with different algorithms.

Based on results in [15-17], PSI algorithm combined with the Pareto optimal set is used to optimize parallel manipulator configuration with limited survey work space in Table 1. Number of steps of the scanning of these parameters is 10 for coordinates $\mathrm{x}, \mathrm{y}, \mathrm{z}$ and is 5 for coordinates $\alpha, \beta$ and $\gamma$. Each one of optimization cycles which runs with the priority of optimization criteria is following: 1) Stiffness of configuration: mean value of the determinant formed from the coordinate axes drives [15]; 2) Number of valid working points of the center of the output links; 3 ) Number of valid working configurations of the robot. The parallel mechanism optimal design process is shown in Figure 5. Figure 6 shows the optimal configuration used for control optimization of parallel manipulator with different control algorithms.
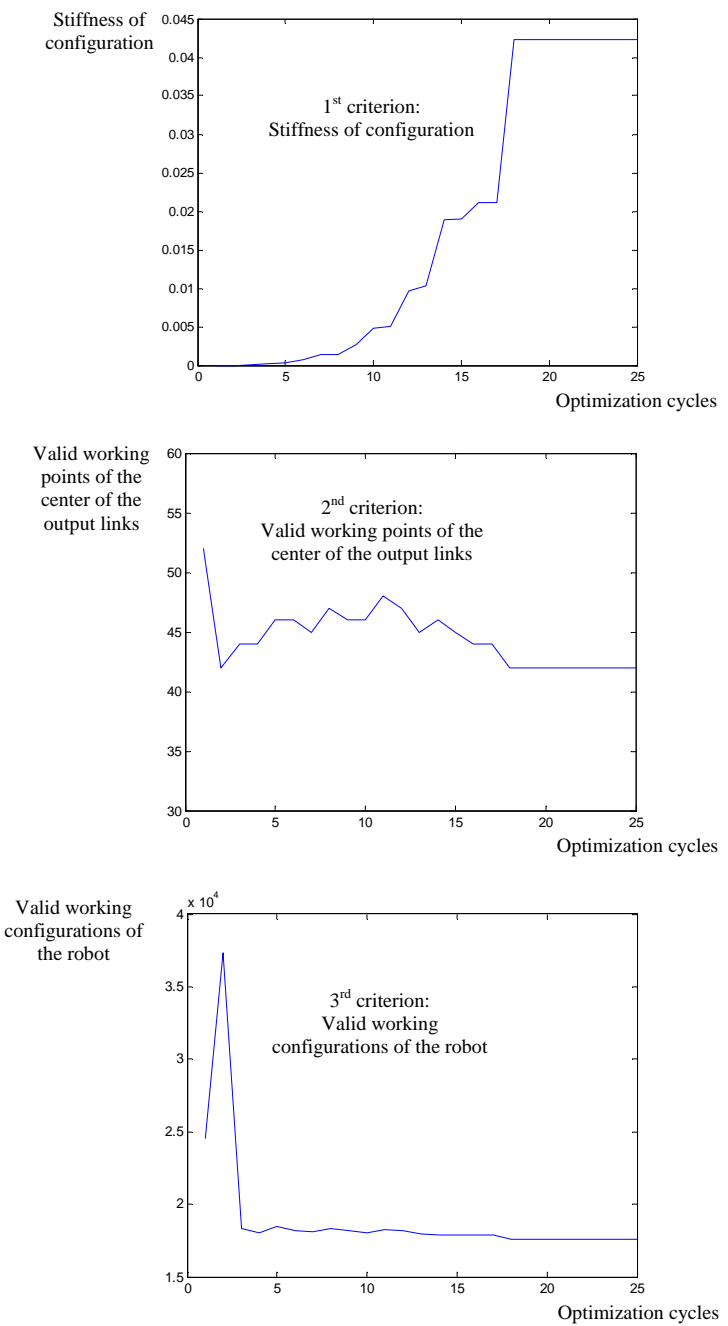

Figure 5: Multi-criteria design optimization process for parallel manipulator (Stewart-Gough Platform).

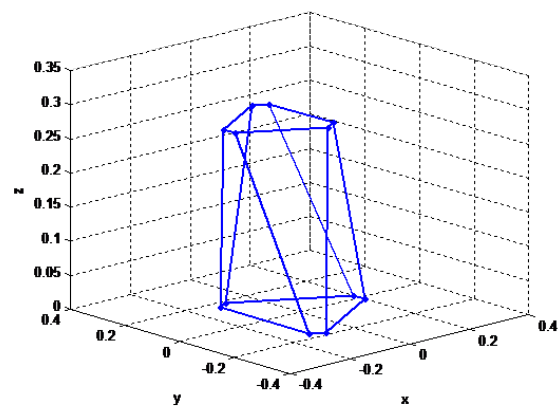

Figure 6: The optimal configuration used for control optimization of parallel manipulator. 
The real-time control model of the parallel manipulator in Simulink is following:

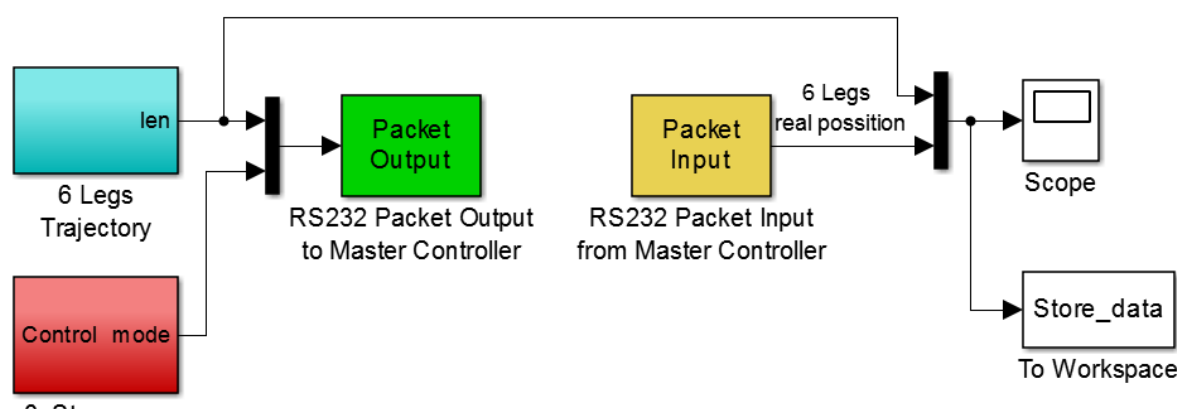

0. Stop

1. PID

2. PID-Fuzzy

3. Fuzzy

4 ....
Stewart Platform

Realtime Control System

Figure 7: The real-time control model in Simulink

Positions of universal joints on the base platform (Bi) are:

$$
B_{i}=\left[\begin{array}{cccccc}
0.1952 & 0.1952 & -0.0601 & -0.1315 & -0.1315 & -0.0601 \\
-0.0432 & 0.0432 & 0.1907 & 0.1475 & -0.1475 & -0.1907 \\
0 & 0 & 0 & 0 & 0 & 0
\end{array}\right]
$$

The initial positions of universal joints on payload platform (Ai) are:

$$
A_{i}=\left[\begin{array}{cccccc}
0.1088 & 0.1088 & 0.0350 & -0.1438 & -0.1438 & 0.0350 \\
-0.1033 & 0.1033 & 0.1459 & 0.0426 & -0.0426 & -0.1459 \\
0.03 & 0.03 & 0.03 & 0.03 & 0.03 & 0.03
\end{array}\right]
$$

In several published papers, PID algorithms were used to control independent actuators of serial mechanisms. For parallel mechanisms, the application of this control algorithm requires the synchronization of position and velocity between interlock actuators. In our system, the moving combination is carried out by distributing control process (see 2.2). Therefore, moving of joints has been ensured correlation and synchronization in the all motion control. The designed PID and Fuzzy-PID algorithms are integrated to actuator controllers with the same conditions and studied parameters in Figure 8 .

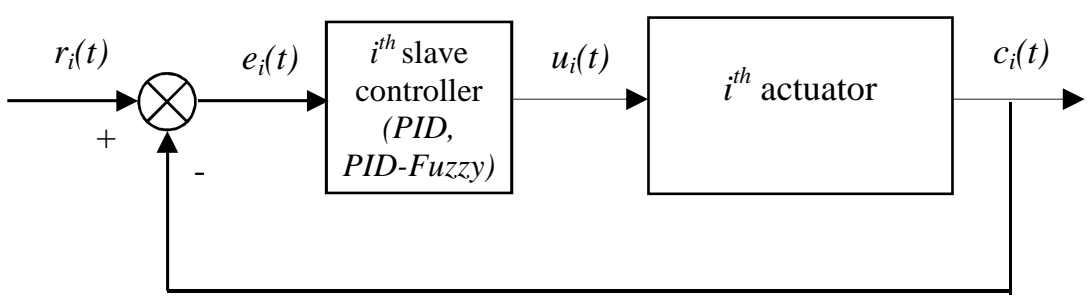

Figure 8: Actuator control model. $r_{i}(t)$ : reference position of $i^{t h}$ actuator. $e_{i}(t)$ : position error of $i^{\text {th }}$ actuator. $u_{i}(t)$ : control force of $i^{\text {th }}$ actuator. $c_{i}(t)$ : real position of $i^{\text {th }}$ actuator. 
The reference motion for the center of the output links control is following:

$$
\begin{aligned}
x_{\text {ang }} & =z_{\text {ang }}=0.02 \sin (0.1 \pi t) ; y_{\text {ang }}=-0.02 \sin (0.1 \pi t) ; \\
x_{\text {pos }} & =0.02 \sin (0.1 \pi t) ; y_{\text {pos }}=0.02 \sin (0.1 \pi t) ; \\
z_{\text {pos }} & =0.33+0.02 \sin (0.1 \pi t) ;
\end{aligned}
$$

The evaluation criteria elaborated to measure the quality of the controllers will be analyzed by the use of the transient response of the first actuator and the synchronization of position and velocity between interlock actuators.

\subsection{PID Controller}

First of all, the traditional PID control algorithm is applied into slave controllers. Control forces of actuators are calculated as:

$$
u(t)=K_{P} e(t)+K_{D} \frac{d e(t)}{d t}+K_{I} \int e(t) d t
$$

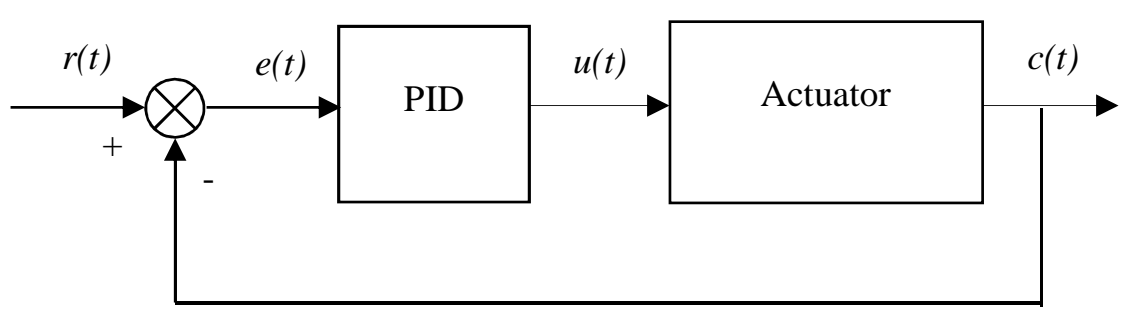

Figure 9: PID controller.

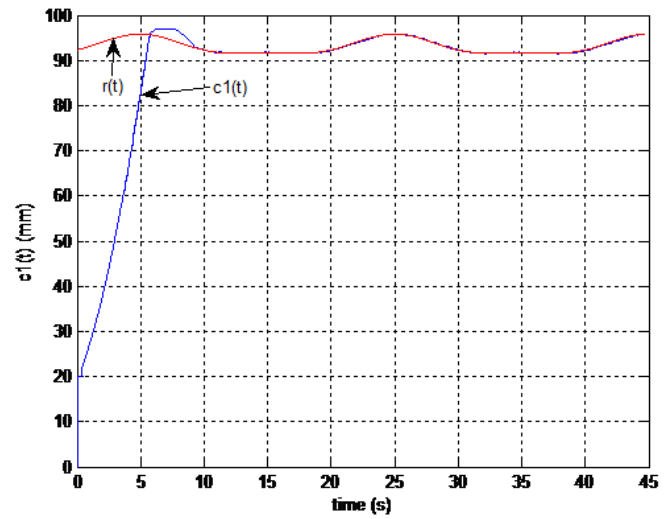

Figure 10: First actuators transient response with PID algorithm.

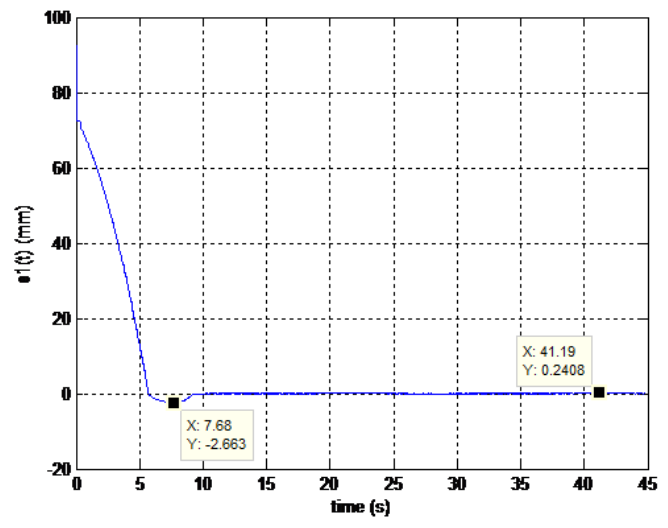

Figure 11: First actuators position error with PID algorithm.

Base on Ziegler-Nichols [31], simulation results [19] and auto-tuning method [32], PID control coefficients are chosen as follows: $K_{P}=105 ; K_{I}=0.2 ; K_{D}=0.1$. The experimental results of transient response and position error of the first actuator (Figure 10, Figure 11) show that PID controller 
has good stability, low overshoot $(\mathrm{POT} \%=2.77 \%)$, low rise time (trise $=5 \mathrm{~s}$ ) with moving distance about $75 \mathrm{~mm}$. But this response has long established time $t_{x l}=9.2 \mathrm{~s}$ and considerable established error $e_{x l}=0.2408 \mathrm{~mm}$. Actuator position error oscillates following the moving of payload platform causes manipulators vibration in the control process. When considering the synchronization of positions and velocity between actuators in Figure 12, the overshoots causing the established time of all actuators are not identical. This effect causes the control force tension between actuators, unsafe for structural mechanics and controller system.

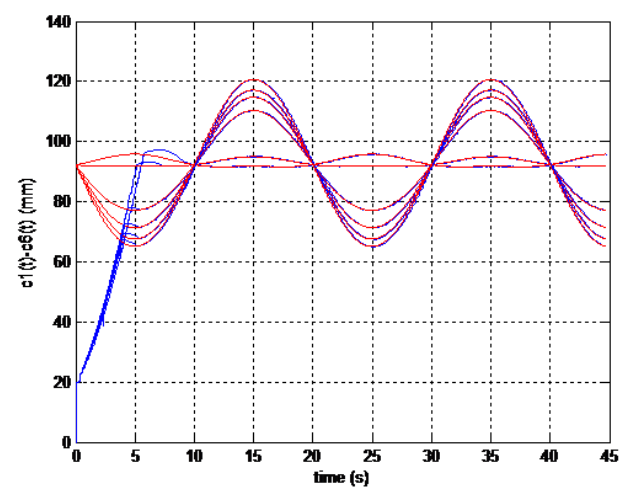

As the results of experiments, PID controller with choosing $K_{P}, K_{I}, K_{D}$ coefficients has sta-

Figure 12: All actuators responses withPID algorithm bility and acceptable quality standards of the system but needs to be improved. As a first step, PID controller is suitable for the control of the motion of the Stewart-Gough Platform.

\subsection{Self-tuning Fuzzy PID controller}

One of the limitations of PID controller is that the $K_{P}, K_{I}$, $K_{D}$ coefficients cannot be changed in the control process. For this reason, the systems response does not often get optimal results and the control of moving of combined actuators is difficult. In order to improve these limitations, a self-tuning Fuzzy PID (Fuzzy-PID) algorithm for slave

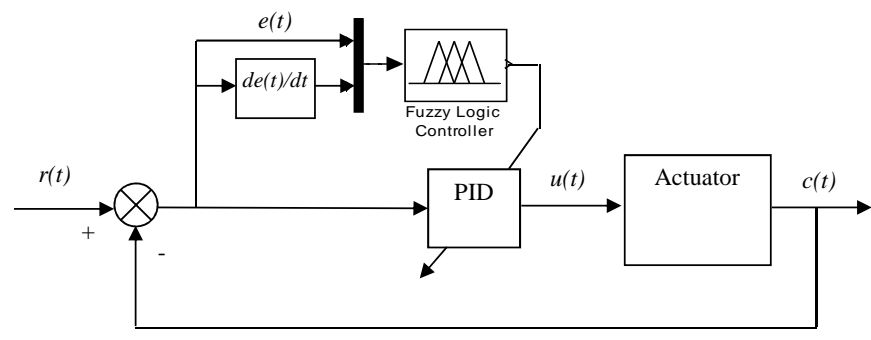

Figure 13: Self-tuning Fuzzy-PID controller controllers [33] is proposed. The simulation results [19] show that Fuzzy-PID controller can change $K_{P}, K_{I}, K_{D}$ coefficients in control process based on fuzzy rules and the change of $e(t)$ and $d e(t) / d t$. The result shows significant improvement in transient response. Figure 13 shows a self-tuning Fuzzy-PID control model with the reference moving (see 3.1). The $K_{P}, K_{D}$ coefficients is in range: $K_{P \min }=30 ; K_{P \max }=150$; $K_{D \min }=0.1 ; K_{D \max }=1$;

Linearize KP, KI, KD coefficients as [19,33], yields:

$$
\begin{aligned}
& K_{P}=\left(K_{P \max }-K_{P \min }\right) \cdot K_{P}^{\prime}+K_{P \min }, \\
& K_{D}=\left(K_{D \max }-K_{D \min }\right) \cdot K_{D}^{\prime}+K_{D \min }, K_{I}=K_{P}^{2} /\left(\beta \cdot K_{D}\right),
\end{aligned}
$$


With $K_{P}^{\prime}, \quad K_{D}^{\prime}$ are defined from fuzzy logic controller (49 fuzzy rules) and normalized in range $[0,1]$, is defined by parameter $K P, K D$ coefficients. Membership functions of $K P, K D$ and $\beta$ have triangular forms with linguistic variables from [19]. The result of FuzzyPID control shows that transient response (Figure 14) and position error of first actuator are significantly better than that of the PID controller (Figure 15). The output response has no overshoot $(\mathrm{POT} \%=0 \%)$, established error is reduced from $e_{x l}=0.2408 \mathrm{~mm}$ to $e_{x l}=$ $0.1076 \mathrm{~mm}$ (reduced $44.68 \%$ ), established time is reduced from $t_{x l}=$ $9.2 \mathrm{~s}$ to $t_{x l}=5.8 \mathrm{~s}$ and the rise time trise is unchanged compared with the case of PID controller. In addition, oscillation of position error is significantly reduced. This result is annulment of vibration and noise of manipulator motion. Beside that the motion synchronization of combined actuators (Figure 16) is significantly improved when the established time is unchanged compared with Section 3.1. Specially, possibilities for safety working of the manipulator are increased when control signals are suddenly changed.

Experimental results in sections 3.1 and 3.2 show that the traditional PID algorithm is optimized by combination with Fuzzy control theory for self-tuning the PID coefficients. These results exactly confirm the conclusions in optimal design and control for the Stewart-Gough platform in $[15-19]$. Thus, it can be affirmed certainly that the optimal design and self-tuning Fuzzy-PID controller used

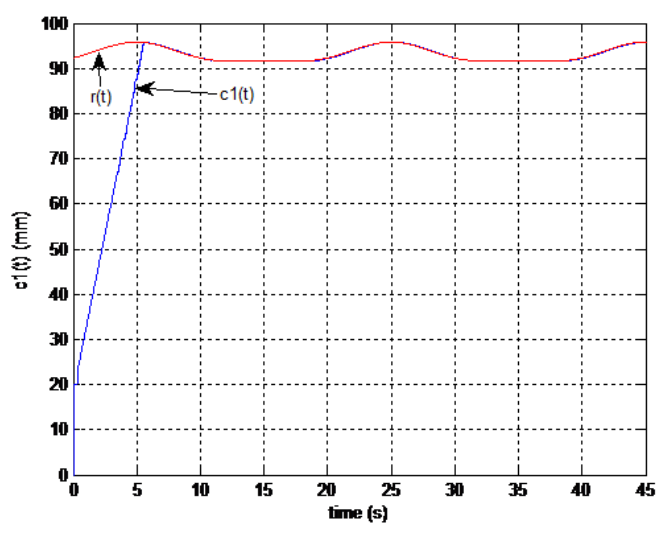

Figure 14: Transient response of first actuator with FuzzyPID algorithm.

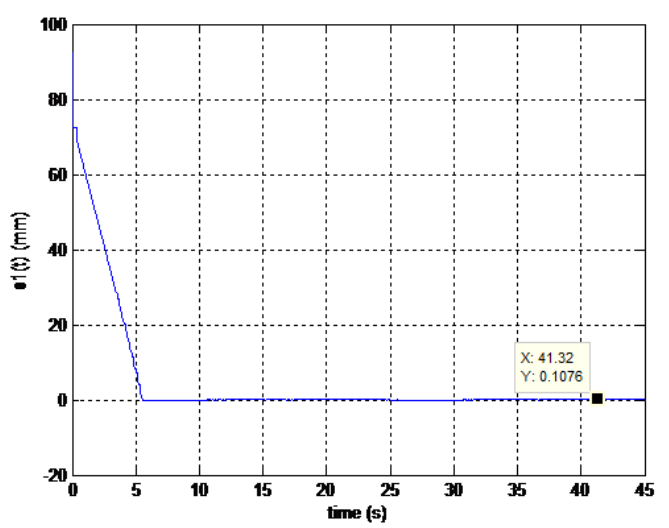

Figure 15: Position error of first actuator with Fuzzy-PID algorithm.

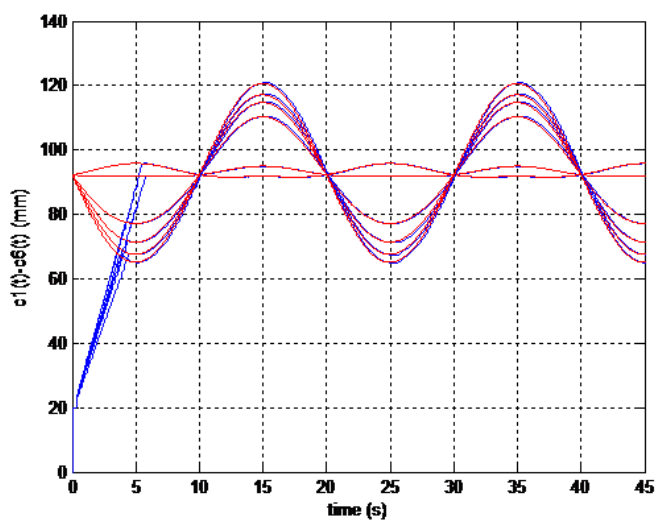

Figure 16: Response of all actuators with Fuzzy-PID algorithm. 
well in practice (Figure 17). The quality standards of the system are improved while the stability and fast control response are still preserved. The experimental system could be applied to other control algorithms in further studies.

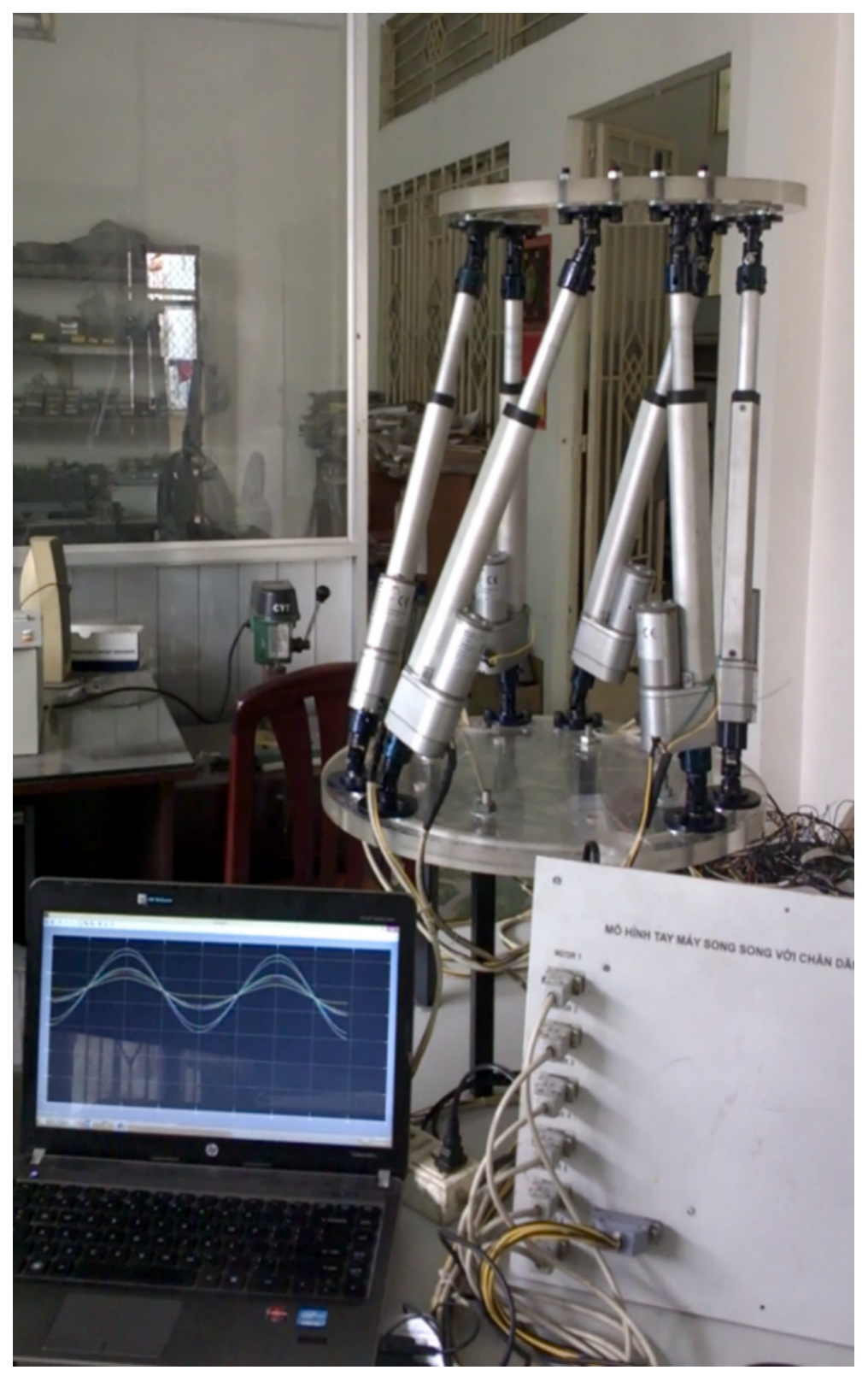

Figure 17: The motion control of the experimental system using Fuzzy-PID controller.

\section{CONCLUSIONS}

The experimental system for the optimization of Stewart-Gough Platform is open, low cost, and is flexible to adjust and choose different control algorithms. This experimental system is used to check simulation results of optimal design and controller realized before in [15-19]. 
The experimental results show that the experimental system has worked well with the optimal configuration designed in fixed workspace. Besides that, the use of self-tuning Fuzzy-PID controller is better compared with a traditional PID controller in motion control of parallel mechanism.

The results of optimization in this paper are executed for one configuration. A load factor and comparison of other control algorithms are not considered. These problems will be considered in subsequent studies.

\section{REFERENCES}

[1] D. Stewart, "A platform with six degrees of freedom," vol. 180, no. 1. SAGE Publications, 1965, pp. 371-386.

[2] J.-P. Merlet, Parallel robots. Springer Science \& Business Media, 2006, vol. 128.

[3] I. Bonev, "Delta parallel robot-the story of success," Newsletter, available at http://www. parallelmic. org, 2001.

[4] D. Yang and T. Lee, "Feasibility study of a platform type of robotic manipulators from a kinematic viewpoint," Journal of Mechanical Design, vol. 106, no. 2, pp. 191-198, 1984.

[5] C. Gosselin and J. Angeles, "Singularity analysis of closed-loop kinematic chains," Robotics and Automation, IEEE Transactions on, vol. 6, no. 3, pp. 281-290, 1990.

[6] D. Zlatanov, R. Fenton, and B. Benhabib, "Identification and classification of the singular configurations of mechanisms," Mechanism and Machine Theory, vol. 33, no. 6, pp. 743-760, 1998.

[7] V. Glazunov, R. Gruntovich, A. Lastochkin, and N. M. Thanh, "Representations of constraints imposed by kinematic chains of parallel mechanisms," in Proceedings of 12th World Congress in Mechanism and Machine Science, 2007, pp. 380-385.

[8] V. Glazunov and N. M. Thanh, "Determination of the parameters and the twists inside singularity of the parallel manipulators with actuators situated on the base," in Proceedings of the 17th CISM-IFToMM Symposium on Robot Design, Dynamics, and Control (Romansy 2008), vol. 17, pp. $467-474$.

[9] N. M. Thanh, V. Glazunov, L. N. Vinh, and N. C. Mau, "Parametrical optimization of parallel mechanisms while taking into account singularities," in 2008 10th International Conference on Control, Automation, Robotics and Vision, 2008, pp. 1872-1877.

[10] N. M. Thanh, L. H. Quoc, and V. Glazunov, "Constraints analysis, determination twists inside singularity and parametrical optimization of parallel mechanisms by means the theory of screws," in Electrical Engineering, Computing Science and Automatic Control, CCE, 2009 6th International Conference on. IEEE, 2009, pp. 89-95.

[11] N. M. Thanh, L. H. Quoc, and V. A. Glazunov, Singularity Analysis, Constraint Wrenches and Optimal Design of Parallel Manipulators, ser. Serial and Parallel Robot Manipulators Kinematics, Dynamics, Control and Optimization, InTech, ISBN: 978-953-51-0437-7, pp. 359$372,2012$.

[12] R. B. Statnikov, Multicriteria design: Optimization and identification. Dordrecht/ Boston / London: Kluwer Academic Publishers, 1999.

[13] S.-D. Stan, V. Maties, R. Balan, and C. Lapusan, "Optimization of a hexapod micro parallel robot using genetic algorithms," in Innovations and Advanced Techniques in Systems, Computing Sciences and Software Engineering. Springer, 2008, pp. 37-42. 
[14] S.-D. Stan, M. Manic, R. Bălan, and V. Mătieş, "Genetic algorithms for workspace optimization of planar medical parallel robot," in IEEE International Conference on Emerging Trends in Computing, IEEE-ICETIC, 2009, pp. 8-10.

[15] N. M. Thanh, V. A. Glazunov, T. C. Tuan, and N. X. Vinh, "Multi-criteria optimization of the parallel mechanism with actuators located outside working space," in Proceedings of International Conference on Control, Automation, Robotics and Vision, ICARCV 2010, 2010, pp. 1772-1778.

[16] N. M. Thanh, N. N. Lam, L. H. Quoc, and N. X. Vinh, "Optimization of parallel manipulator using genetic algorithm," Journal of Computer Science and Cybernetics, vol. 27, no. 1, pp. 93-106, 2011.

[17] N. M. Thanh, N. X. Vinh, L. H. Quoc, and N. N. Lam, "Design optimization of parallel manipulator using genetic algorithm combined with optimal pareto set," in Proceedings of Vietnam Conference on Control and Automation, VCCA-2011, 2011, pp. 207-214.

[18] N. X. Vinh, N. M. Thanh, L. H. Quoc, and N. N. Lam, "Determination singularity configuration set of parallel manipulator using screw theory," in Proceedings of the 6th Vietnam Conference on Mechatronics, VCM-2012, 2012, pp. 754-762.

[19] — - "Control parallel manipulator using fuzzy theory combined with genetic algorithm," in Proceedings of the 2nd Vietnam Conference on Control and Automation, VCCA-2013, 2013, pp. 305-313.

[20] G. Lebret, K. Liu, and F. L. Lewis, "Dynamic analysis and control of a stewart platform manipulator," Journal of Robotic systems, vol. 10, no. 5, pp. 629-655, 1993.

[21] Z. Zhou, W. Meng, Q. Ai, Q. Liu, and X. Wu, "Practical velocity tracking control of a parallel robot based on fuzzy adaptive algorithm," Advances in Mechanical Engineering, vol. 5, p. 574896, 2013.

[22] P. V. B. Ngoc, V. Q. Thang, D. T. Thang, and P. A. Tuan, "Simulation and design of hexapod for mechanical outworks," in Proceedings of the 2nd Vietnam National Conference on Mechatronics, VCM-2004, 2004, pp. 21-26.

[23] — - "Design of parallel manipulator (hexapod) for precise mechanical outworks," in Proceedings of the 2nd Vietnam National Conference of Mechanics, VCM-2004, 2004.

[24] D. C. Huan, V. T. D. Huong, V. M. Hung, D. T. N. Oanh, N. H. Thuy, and P. A. Tuan, "Development of a control system for hexapod," in Proceedings of the 8th International Conference on Mechatronics Technology, ICMT 2004, 2004, pp. 133-138.

[25] T. T. T. Ha and H. T. Tam, "Application of parallel robots in coordinate measuring cmmmachine," in Proceedings of the 6th Vietnam Conference on Automation, VICA-6, 2005, pp. $44-45$.

[26] N. T. Phuc, T. M. Nghia, and N. D. Nin, "Research and develop hexa parallel robot," in Proceedings of the 6th Vietnam Conference on Automation, VICA-6, pp. 408-413.

[27] V. M. Hung, D. T. N. Oanh, N. H. Thuy, and P. A. Tuan, "The multi-axis position control for parallel robot - hexapod PR6-01," in Proceedings of the 6th Vietnam Conference on Automation, $V I C A-6,2005$, pp. 64-65.

[28] N. H. Thai, "Experimental production of robot hexaglide," in Proceedings of the 3rd Vietnam Conference on Mechatronics, VCM-2006, 2006, pp. 206-210. 
[29] L. H. Quoc and N. M. Thanh, "Modeling of parallel manipulator system and building of machining center on the cnc- axis milling machine," in Proceedings of Vietnam Conference on Control and Automation, VCCA-2011, 2011, pp. 200-206.

[30] L. Q. Ha, "Design and production of parallel robot with actuators located outside working space for industrial application," Report of Technical project of Industry and Commerce Ministry, Tech. Rep., 2012.

[31] J. G. Ziegler and N. B. Nichols, "Optimum settings for automatic controllers," Transactions ASME, vol. 64, no. 11, pp. 759-768, 1942.

[32] A. Leva, C. Cox, and A. Ruano, "Hands-on pid autotuning: a guide to better utilisation," in IFAC Professional Brief. IFAC, 2001. [Online]. Available: http://www.ifac-control.org/

[33] Z.-Y. Zhao, M. Tomizuka, and S. Isaka, "Fuzzy gain scheduling of pid controllers," Systems, Man and Cybernetics, IEEE Transactions on, vol. 23, no. 5, pp. 1392-1398, 1993.

Received on January 28, 2015

Revised on June 12, 2015 
